\title{
Paradigmas de política penal e sentido econômico da população: das punições corporais às UPPs*
}

Paradigms of penal policy and the economic significance of population: from corporal punishments to the Police Pacification Unit

\section{Pedro Rocha de Oliveira**}

\begin{abstract}
Resumo - Uma ideia central da criminologia materialista é que a política penal de uma determinada sociedade - o que é crime, quanto e como se pune - não resulta de concepções jurídicas, mas é função de sua viabilidade e necessidade econômica. Partimos dessa ideia para analisar a transição histórica sucessiva de três paradigmas punitivos da sociedade moderna - os castigos físicos, os trabalhos forçados e o encarceramento. Seguindo e desenvolvendo as leituras de Rusche/ Kirchheimer, esses paradigmas são apresentados como políticas de Estado relacionadas a alterações no regime de acumulação capitalista e da demanda de força de trabalho. Esse raciocínio é estendido a formas contemporâneas de política penal - em especial, o controle territorial de espaços de pobreza pela polícia no município do Rio de Janeiro - para sugerir um quarto paradigma dessa política, ligado a alterações no sentido econômico da população no capitalismo contemporâneo.

Palavras-chave: criminologia crítica; política penal; história; sociedade moderna; Regimes de acumulação capitalista; Georg Rusche; Otto Kirchheimer.
\end{abstract}

\begin{abstract}
A central idea in materialist critical criminology is that the criminal policy of a given society - what constitutes a crime, the amount and way of punishment - does not result from legal concepts, whereas it is due to its feasibility and economic necessity. We take this idea as a starting point to analyze the successive historical transition of three punitive paradigms of modern society - physical punishment, forced labor, and imprisonment. Following and developing readings of Rusche/ Kirchheimer, these paradigms are presented as state policies related to changes in the regime of capital accumulation and in the demand for labor force. This reasoning is extended to contemporary forms of criminal policy - in particular, the territorial control of poverty areas by the police in the municipality of Rio de Janeiro - to suggest a fourth
\end{abstract}

\footnotetext{
* Este artigo seria impensável sem as numerosas conversas com Clarice Salles Chacon.

** Doutor em filosofia pela PUC-Rio. Professor adjunto do Departamento de Filosofia da Universidade Federal do Estado do Rio de Janeiro (UNIRIO). Co-autor do livro Até o último homem: visões cariocas da administração armada da vida social (Boitempo, 2013). Correspondência: UNIRIO - Centro de Ciências Humanas e Sociais: Av. Pasteur, 458 - Urca, Rio de Janeiro/RJ. CEP: 22290-240. Email: <oliveira.rocha.pedro@gmail.com>
} 
paradigm of this policy, linked to changes in the economic sense of the population in contemporary capitalism.

Keywords: critical criminology; penal policy; history of modern society; regimes of capital accumulation; Georg Rusche; Otto Kirchheimer.

\section{Introdução}

Um dos alicerces da racionalidade burguesa, continuamente evocado pelos ideólogos da sociedade moderna para refletir e ordenar tanto as operações privadas quanto os negócios públicos, é o princípio da equivalência. Enraizado na fantasia da compra e venda a preço justo ${ }^{-}$que Marx denuncia através de sua teoria da mais-valia - esse princípio é universalmente entranhado no imaginário social, e oferece-se instintivamente para balizar o pensamento numa miríade de assuntos, desde a reciprocidade nas relações interpessoais, até a relação entre crime e castigo. Neste último campo, a punição aparece como o complemento matemático e moral do crime: seu rigor deve ser proporcional à gravidade do crime. Essa criminologia burguesa teve suas primeiras expressões formais na pena do lluminismo especialmente a partir da obra Dos delitos e das penas (1764), de Cesare Beccaria - com repercussões até a criminologia positivista dos séculos XIX e XX. Contra ela, entretanto, um dos princípios da chamada criminologia crítica é que a suposta racionalidade irrecorrível de tal equivalência é uma ficção: a pena não pode derivar do crime, uma vez que o próprio crime é uma construção social enraizada na capacidade e na necessidade social de punir. A essa ideia, a corrente materialista da criminologia crítica acrescenta, ademais, que tal capacidade ou necessidade deve ser compreendida em termos econômicos. Na formulação de Georg Rusche e Otto Kirchheimer (2004, p. 20-21),

todo sistema de produção tende a descobrir formas punitivas que correspondam às suas relações de produção. [...] a origem e a força dos sistemas penais, o uso e a rejeição de certas punições e a intensidade das práticas penais, [...] são determinadas por forças sociais, sobretudo pelas forças econômicas e, consequentemente, fiscais.

Ou, em outras palavras: "somente um desenvolvimento específico das forças produtivas permite a introdução ou a rejeição de penalidades correspondentes" (RUSCHE; KIRCHHEIMER, 2004, p. 20-21).

Uma dupla sugestão está contida nessa posição. Por um lado, se aceitamos que toda pena precisa ser possível economicamente, as práticas penais devem estar enraizadas no procedimento econômico das sociedades em que ocorrem, de tal modo que sua elaboração e manutenção não podem entrar em conflito com tal procedimento. Assim, a análise de concepções jurídico-penais deve passar não apenas pelos discursos que as pretendem fundamentar racionalmente, eticamente etc., mas, sobretudo, pelos liames 


\section{ADVistg all PaUtg}

\} PARADIGMAS DE POLÍTICA PENAL E SENTIDO ECONÔMICO - OLIVEIRA, P. R. \}

DOI: $10.12957 /$ REP.2016.25402

às vezes silenciosos que as prendem à produção de riqueza. Por outro lado, se a pena deve estar em harmonia fundamental com a produção de riqueza, isso significa que toda prática penal revelará algo fundamental sobre a sociedade na qual ela existe.

Assim, por exemplo, a escravidão como forma de punição não pode ser entendida apenas através do discurso que deprecia as raças escravizadas, ou na lógica que converte o crime em dívida de trabalho, mas precisa ser vista enquanto conectada a uma forma de produzir riqueza que cria uma demanda real e constante de força de trabalho não remunerada. Ou seja: é possível dizer, de uma sociedade que adota a escravidão como prática penal, que existe, nela, o problema sistêmico de uma demanda de força de trabalho não remunerada.

À luz desse raciocínio, o que pretendemos realizar aqui é uma análise de formas paradigmáticas de punição da sociedade moderna. Falamos de "sociedade moderna" porque pretendemos, com tal análise, abarcar a produção capitalista em sentido amplo, desde seu formato agrário exportador até a configuração contemporânea. E falamos de "formas paradigmáticas" porque trataremos justamente de esquemas punitivos que revelam aspectos fundamentais dos diferentes regimes de acumulação capitalistas.

O presente trabalho, portanto, é guiado pela seguinte pergunta fundamental: o que as formas punitivas nos dizem a respeito das diferentes etapas do desenvolvimento do capitalismo? Ora, ao tomarmos essas formas punitivas em conjunto, salta aos olhos sua estreita conexão com variações no caráter do trabalho. Percebemos que os castigos físicos da primeira modernidade inglesa - paradigmaticamente, as mutilações e açoites com que se puniam os "vagabundos" na época da privatização das terras e dissolução das relações de produção feudais - correspondem a formas de produção de mercadoria que funcionam com uma força de trabalho limitada, enquanto que o trabalho prisional nos Estados Unidos do século XIX está inserido num contexto de industrialização rápida, competição internacional por mercados e alta demanda de força de trabalho. É nesses termos que falaremos aqui de um sentido econômico da população, ou seja, da relevância quantitativa da população em geral para a formação de forças de trabalho com perfis determinados, desde o ponto de vista da produção de mercadorias.

\section{O advento moderno da discriminação econômica e da população mutilável}

Nos estudos sobre população carcerária, um dos aspectos usualmente evocados pelos sociólogos é o nível educacional dos prisioneiros. A maior parte deles, mesmo nos países "desenvolvidos", não possui quase nenhuma instrução funcional (O'BRIEN, 1998, p. 179). Esse é um dado 


\section{heVistg ent paUtg}

\} PARADIGMAS DE POLÍTICA PENAL E SENTIDO ECONÔMICO - OLIVEIRA, P. R.\}

DOI: $10.12957 /$ REP.2016.25402

curioso, constante e fundamental na história da punição na sociedade moderna. Os registros mais antigos que essa sociedade produziu sobre punidos e encarcerados listam-nos frequentemente em termos de sua falta de habilidade profissional (SHARPE, 1999, p. 263). Isso nos lembra como, na sociedade capitalista, desde suas origens, o poder repressivo do Estado foi exercido sobretudo contra os mais pobres. Porém, mais que isso, é importante observar como a figura do criminoso punível desprovido de habilidade expressa eloquentemente a funcionalização econômica da vida humana pela sociedade moderna.

Perceber gente em termos de sua capacidade ou não de realizar um trabalho mais ou menos especializado é um procedimento relativamente recente na história da humanidade. Na sociedade agrária pré-moderna, com exceção dos fisiologicamente impedidos, todos estavam envolvidos no processo de produção. Viver era estar inserido na divisão de trabalho nas esferas da família e do grupo: saber pescar, caçar, plantar, colher, processar os alimentos, cuidar das ferramentas etc. - habilidades que os punidos sem-habilidade da alvorada da modernidade certamente possuíam. Mas aquela categoria, no fim das contas, não expressava a incapacidade do indivíduo de subsistir na sociedade agrária pré-moderna que estava então sendo extinta na marra.

Comunidades cujos vínculos sociais estavam sedimentados na dependência mútua - no fato de que todos e cada um precisavam participar das tarefas de produção material - simplesmente não possuíam instituições frente às quais a contribuição de um indivíduo na divisão social do trabalho pudesse ser avaliada e potencialmente reprovada. A exclusão socioeconômica através do banimento ou da execução eram punições extremas. Em tempos de paz, esperava-se naturalmente que todos os indivíduos trabalhassem e fazia-se o possível para evitar a diminuição do número de "braços aptos".

Quando os vínculos imediatos da subsistência foram quebrados pela privatização da terra na alvorada da sociedade moderna, apareceu, a reboque, a incapacidade constitutiva de participar da produção material enquanto propriedade subjetiva. O Estado moderno desenvolveu uma série de instituições voltadas para a discriminação econômica, ou seja, instituições ocupadas com a relativização da existência de indivíduos e populações, com base na avaliação de sua funcionalidade econômica. A partir de então, só participa da produção social (e vive) quem é capaz de contribuir para o enriquecimento alheio. Submetida ao primado da quantificação, a sociedade passa a ser pensada como um aglomerado numericamente determinado: a população torna-se uma preocupação da administração estatal - em especial, a população economicamente supérflua.

A política penal da alvorada da sociedade moderna foi o recurso administrativo por excelência para lidar com essa população. Ela podia ser submetida a punições que destruíssem o corpo laborante, visto que, de 


\section{ADVistg all PaUtg}

\} PARADIGMAS DE POLÍTICA PENAL E SENTIDO ECONÔMICO - OLIVEIRA, P. R. \}

DOI: $10.12957 /$ REP.2016.25402

qualquer forma, não trabalhariam. O discurso jurídico que sustentava essa política penal - Martinho Lutero foi um de seus mais loquazes arautos evocava sem pudores a superfluidade econômica daqueles que ela vitimava, e falava, ainda, do suposto efeito dissuasivo alcançado pelas mãos cortadas, olhos furados, línguas arrancadas, pés decepados e marcações a ferro quente, para não falar das execuções na forca ou por meio de torturas elaboradas com tanto afinco que se tornavam espetáculos (RUSCHE; KIRCHHEIMER, 2004, p. 40). Expulsos da vida agrária e militarmente impedidos de retornar a ela, afastados no máximo em uma ou duas gerações da experiência brutal da privatização da terra, os sem-habilidade vitimados por essas práticas eram frequentemente descritos, ademais, com os termos que deram origem à palavra "vagabundo": alguém que (uma vez desenraizado de seu lugar original contra sua vontade!) vaga de lugar em lugar, vivendo de bicos, restos e caridade.

A sociedade feudal e de subsistência era reorganizada em termos da produção de mercadorias agrárias, na qual a demanda por força de trabalho era mínima. As multidões expulsas da terra engrossavam um exército de mão de obra de reserva que tornava os salários tão baixos a ponto de fazer com que a indigência fosse preferível (PATRIQUIN, 2007, p. 99). O trabalho nas manufaturas não apenas estava limitado a alguns centros urbanos, como requeria as destrezas específicas em referência às quais a população punível era designada desprovida de habilidade. Em suma: era fácil tornar-se economicamente supérfluo e, portanto, mutilável. A hedionda ironia se completava com o fato de que, uma vez marcado a ferro ou privado de sua integridade física, o vagabundo tinha ainda menos chances de encontrar trabalho. Indivíduos marcados, em alguns lugares, eram obrigados a uma espécie de escravidão, mas a abundância de mão de obra "livre" era tão grande no período que os custos de manutenção de uma vida a mais não valiam a pena. Assim, o destino dos marcados e dos mutilados era a reincidência no crime de não ter nada o que comer, portanto, novas mutilações e, finalmente, a execução.

$\mathrm{Na}$ Europa dos séculos XVI e XVII, foi comum aplicar-se a pena capital para punir os mais banais crimes contra a propriedade, tais como o roubo. Na Inglaterra da Rainha Elizabeth, os ladrões e os vagabundos eram enforcados às centenas (RUSCHE; KIRCHHEIMER, 2004, p. 37). Esquartejamentos e outras práticas mais elaboradas também foram empregados, mas eram sobretudo a marca das execuções dos revoltosos: não faltaram levantes populares que tentassem reverter o processo de privatização da terra, clamando pela manutenção imediata da vida através do exercício de suas não habilidades. Afinal, o trabalho, na sociedade produtora de mercadorias, não é simplesmente o esforço de satisfação de necessidades, mas tem um significado muito preciso - a acumulação de riqueza -, significado esse que precisou ser imposto sobre a humanidade através da violência, e necessita de uma violência contínua para se manter vigente. 


\section{A manufatura e a casa de correção}

Isso tudo quer dizer que a socialização através do trabalho assalariado tem limitações intrínsecas, donde o advento da quantificação da população e da população economicamente supérflua. Trata-se de uma condição geral da sociedade moderna: enquanto existir propriedade privada e trabalho assalariado, a satisfação de necessidades está condicionada à inserção no processo econômico de produzir mercadorias para acumular a riqueza alheia. Assim, em termos lógicos, a população economicamente supérflua é uma constante na história da sociedade moderna. Por outro lado, diferentes políticas populacionais - e, portanto, políticas penais projetaram perfis diferentes para essa população economicamente supérflua. A passagem do paradigma das mutilações e execuções para o paradigma do encarceramento mostra bem isso.

Na Inglaterra, o problema da implantação de operações econômicas no Novo Mundo, no final do século XVI, criou uma demanda populacional cuja necessária influência na política penal foi logo percebida pelos pensadores da colonização (HILL, 1980, p. 98; LINEBAUGH; REDIKER, 2011, p. 56): a deportação e os trabalhos forçados começaram a crescentemente substituir as mutilações e o extermínio pela forca. Intensificou-se a condenação à servidão nas galés e a outras variedades de escravidão militar: além da demanda populacional, a aptidão física, mais do que a natureza do crime, determinava a aplicação dessas penas (RUSCHE; KIRCHHEIMER, 2004, p. 85-88). Ademais, em toda a Europa, com as bênçãos dos príncipes e patrícios, organizaram-se bandos de caçadores de escravos que, através do rapto de vagabundos - na prática, qualquer um que fosse suficientemente vulnerável - encheram de homens, mulheres e crianças os porões dos navios destinados à América, caracterizando o primeiro esforço de colonização como uma gigantesca operação penal.

No continente europeu, na segunda metade do século XVII, a expansão da manufatura combinou-se à diminuição do crescimento demográfico resultante das catastróficas influências do período anterior. A Guerra dos 30 Anos aniquilou cerca de um terço da população nos estados alemães. A destruição na infraestrutura agrícola e de circulação foi generalizada; fome e epidemias espalharam-se pelo continente. Nessa altura, aí como na Inglaterra, a deportação sistemática começou a ser gradualmente substituída por uma política de controle da circulação da população: agora, marcados a ferro eram aqueles que - oriundos dos meios urbanos ou da quinta ou sexta geração de desterrados rurais sem-habilidades - deixavam sem autorização seu lugar de origem para procurar melhor trabalho e salário (RUSCHE; KIRCHHEIMER, 2004, p. 44-47). Foi comum em toda parte que tais marcações qualificassem-nos para a servidão por longos períodos em oficinas individuais ou municipais, onde muitas vezes viviam acorrentados e sem nenhuma paga além de refeições especialmente miseráveis numa 


\section{ADVistg all PaUtg}

\} PARADIGMAS DE POLÍTICA PENAL E SENTIDO ECONÔMICO - OLIVEIRA, P. R. \}

DOI: $10.12957 /$ REP.2016.25402

época em que o crescimento das cidades impunha aumentos crescentes ao preço dos alimentos. A política estatal de manutenção e incremento de população teve expressões curiosas no período: na Inglaterra, o puritanismo parlamentar foi derrotado por uma tolerância monárquica às festas populares regadas a cerveja, num claro incentivo ao surgimento de oportunidades para a "fornicação"; na Prússia de Frederico II, o clero foi proibido de punir as mães solteiras (RUSCHE; KIRCHHEIMER, 2004, p. 49-50).

Essa época também assistiu à generalização das casas de correção. A primeira delas foi a de Bridewell, Londres, construída em 1555, quando a manufatura já havia se estabelecido firmemente na capital econômica da precoce Inglaterra. Instituições semelhantes espalharam-se pela Europa insular e pelo continente nas décadas seguintes; foram exportadas para o Novo Mundo, onde continuaram funcionando, com certas modificações, até o século XIX. Misturando a assistência aos pobres com a servidão penal, as casas de correção são o resultado de uma inflexão da política assistencialista do absolutismo.

Desde o início da dissolução da sociedade agrária de subsistência, e especialmente em resposta aos numerosos levantes populares e fenômenos de banditismo, o complemento das mutilações e enforcamentos era a caridade. Na Inglaterra, o rompimento com a Igreja Católica nas primeiras décadas do século XVI havia desarticulado as redes tradicionais de auxílio aos necessitados. Através das famosas Leis dos Pobres, o lugar deixado vago pelos monastérios destruídos foi ocupado por diversas ações do Estado Tudor, cujo caráter pioneiramente empreendedor possibilitou, ulteriormente, a conversão dos abrigos em oficinas, em parceria com a característica nobreza capitalista inglesa. Logo, variações desse tema básico pipocaram nos Países Baixos, na França e nos estados alemães.

A casa de correção concentrava várias funções socioeconômicas fundamentais na alvorada do capitalismo. Na medida que encarcerava os pobres - sobretudo os condenados por vagabundagem ou crimes contra a propriedade -, a casa de correção atingia um alto grau de controle populacional direto. É importante observar que, até então, apenas os meios eclesiásticos - nos quais a pena capital era proibida - praticavam o encarceramento como forma de punição: onde existiam cadeias, elas serviam apenas aos detidos que aguardavam julgamento e cuja punição teria a forma ou bem de multas ou açoites, ou bem das horríveis práticas descritas acima. Encerrados nas casas de correção, os sem-habilidade, aniquiláveis até algumas gerações atrás, eram agora obrigados a aplicar sua força de trabalho em atividades manufatureiras.

Assim, segundo o discurso de então, além das refeições miseráveis e acomodações insalubres e entulhadas, a "caridade" de que eram alvo era estendida, ainda, ao treinamento profissional. Isso não significava apenas que os sem-habilidade eram convertidos em habilidosos: significava, também, que, nas casas de correção, a sociedade produtora de mercadorias 


\section{heVistg ent paUtg}

\} PARADIGMAS DE POLÍTICA PENAL E SENTIDO ECONÔMICO - OLIVEIRA, P. R.\}

DOI: $10.12957 / R E P .2016 .25402$

tinha a chance de incutir, através da violência física e psicológica intensa e constante, o hábito do trabalho regular numa população que, ainda recentemente egressa da vida agrária, regulava seus ritmos de atividade com base nas necessidades do corpo humano e nos ciclos naturais, e não no tempo abstrato guiado pelo relógio para a maximização do lucro alheio (THOMPSON, 2010, p. 354-355). Em troca de todas essas admiráveis benesses, o prisioneiro pagava parte de seu salário, todo ele, ou, ainda, contraía uma dívida a ser paga através de mais trabalho gratuito por um tempo adicional ao de sua pena.

Assim como o próprio surgimento das casas de correção, a natureza dessa pena, bem como sua duração, variaram historicamente em função não da taxa de criminalidade - difícil de medir, de qualquer forma, dado quão generalizada era a mendicância e a migração na alvorada do capitalismo - mas da demanda de força de trabalho. De fato, os atos estatais que fundavam ou permitiam fundar as casas de correção e instituições semelhantes muitas vezes expressavam com todas as letras a preocupação das autoridades com a promoção da manufatura (RUSCHE; KIRCHHEIMER, 2004, p. 71). Desse modo, ao lado da colonização, outro evento fundamental da era moderna, a manufatura também foi, em larga medida, uma operação penal.

\section{A fábrica e a prisão}

A casa de correção é, portanto, a marca de um período em que o desenvolvimento da manufatura causa uma alteração no sentido econômico da população: as legiões de vagabundos sem-habilidades do período anterior adquirem o sentido econômico de força de trabalho em alta demanda. Com a diversificação das técnicas de produção e dos ramos manufatureiros, essa situação geral se manteve até o século XVIII. Mas, então, a introdução da máquina a vapor alterou o quadro significativamente: o aumento de produtividade rapidamente alcançado pelo ritmo regular e constante do novo maquinário e pela divisão do trabalho por tarefas destruiu a manufatura de escala doméstica, o que resultou no reaparecimento da multidão de desempregados do início da era moderna e uma queda vertiginosa dos salários.

As casas de correção tentaram adaptar-se ao maquinário industrial; no entanto, a constante flutuação nas demandas de mercadorias tornava economicamente ineficiente a manutenção de uma população prisioneira que não podia ser realmente demitida, visto estar cumprindo pena! A população mudava de sentido econômico novamente: no século XIX, com a industrialização, um mercado de bens de consumo razoavelmente bem desenvolvido e a competição constante com novos empreendedores, o fundamento da relevância econômica da população em geral é sua capa- 


\section{ADVistg all PaUtg}

\} PARADIGMAS DE POLÍTICA PENAL E SENTIDO ECONÔMICO - OLIVEIRA, P. R. \}

DOI: $10.12957 /$ REP.2016.25402

cidade de ser contratada e demitida conforme as exigências do mercado. A política penal se adapta a isso transformando a casa de correção, esse espaço de trabalhos forçados, na prisão moderna, o armazém de gente. Nesse contexto, e para desempenhar tal função, os sistemas penais do século XIX trabalharão sobretudo com penas curtas, porém aplicadas frequentemente. $\mathrm{Na}$ Inglaterra, cunhou-se a expressão "prisão perpétua a prestações" para descrever essa política penal (MCCONVILLE, 1998, p. 133).

É verdade que experimentos com o trabalho industrial prisional foram realizados no início do século XIX, mas - para além do da utilização do trabalho do prisioneiro na manutenção da própria prisão - só tiveram sucesso em situações muito especiais e por períodos curtos. Os Estados Unidos, onde a disponibilidade de terras livres ofereceu, até o início do século XX, uma alternativa ao assalariamento, tiveram sua fase manufatureira e seu período de industrialização marcados por uma alta demanda de força de trabalho. Aí, o trabalho industrial carcerário e a manutenção de uma população de trabalhadores cativos vivendo em condições subumanas encontraram uma opção economicamente vantajosa. Nos estados do Sul, ademais, o trabalho prisional rural - com efeito, em funcionamento até os dias de hoje - serviu, em combinação com o sistema de segregação racial, para prolongar as vantagens econômicas da escravidão na expansão da fronteira agrícola e na construção da malha rodoviária (ROTMAN, 1998, p. 157; WACQUANT, 2013, p. 339).

Especialmente na Inglaterra, o que apareceu como alternativa ao trabalho industrial prisional economicamente inviável foi o trabalho prisional improdutivo. As façanhas mecânico-administrativas da Revolução Industrial foram, aí, aplicadas com empertigado sadismo para a produção de um maquinário de tortura que proporcionava ao prisioneiro o rebaixamento do nível de vida através da exaustão e da monotonia do trabalho e do incremento das privações da miséria material - além de continuar o projeto do período anterior de administração da vida, inculcando o hábito do trabalho árduo e regular. Mal alimentados, com frio, dormindo no chão, os prisioneiros eram obrigados a passar a maior parte de seus dias cavando buracos que depois seriam enchidos de novo, ou movimentando com os braços e pernas engrenagens inúteis atreladas a pesos colossais. Punições adicionais por quebra da rígida disciplina incluíam, além de açoites, tormentos específicos da sociedade industrial, tais como a privação do sono. Os antepassados dos nutricionistas e dos fisiologistas de hoje calculavam os limites psicofísicos do desconforto, para maximizar o sofrimento sem destruir os corpos, de modo a tornar a punição contínua possível (MCCONVILLE, 1998, p. 134-146).

As primeiras décadas do século XIX viram surgir, desenvolver-se e expandir-se, a partir dos Estados Unidos, uma ciência prisional de inspiração Quaker, que apostava no isolamento e na dessocialização dos prisioneiros. Celas individuais, construídas em alas geometricamente dispostas, 


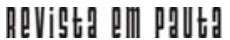

\} PARADIGMAS DE POLÍTICA PENAL E SENTIDO ECONÔMICO - OLIVEIRA, P. R. \}

DOI: $10.12957 /$ REP.2016.25402

deram expressão e viabilidade arquitetônica para o projeto moderno de administrar a vida dos aprisionados. Mas, em toda parte, já na metade do século XIX, o crescimento contínuo das taxas de encarceramento colocou em cheque a tétrica elegância desse sistema (ROTMAN, 1998, p. 152; O'BRIEN, 1998, p. 181). Passadas apenas as primeiras décadas de sua concepção, a superpopulação constante e uma degradação institucional progressiva tornou-se - e continua sendo - a regra do sistema prisional ocidental, mesmo nos países ditos desenvolvidos. A despeito das sofisticadas controvérsias dos penologistas e as declarações judiciais a respeito do efeito pedagógico da pena, aquela degradação foi, indubitavelmente, a força social determinante na conformação da prisão: por fazer parte do enxugamento dos gastos estatais advindo da modernização administrativa do século XIX (RUSCHE; KIRCHHEIMER, 2004, p. 148), trata-se de uma degradação calculada e economicamente determinada.

Em paralelo a esses desenvolvimentos na política penal, o século XIX assistiu à sofisticação do discurso científico sobre a superpopulação, especialmente em sua terra pátria, a Inglaterra, onde seu exponente mais famoso foi o Reverendo Thomas Malthus (1766-1834). As políticas de expansão populacional do período anterior foram substituídas por um novo discurso austero que encarava a população de miseráveis desempregados e empregados miseravelmente pagos como um recurso econômico de quantidade salutarmente flutuante, bem como regulada automaticamente através do perecimento pela fome e pela doença, segundo flutuações no preço da força de trabalho.

Do outro lado da luta de classes, as organizações de trabalhadores, bebendo do ideário universalista circulante desde o final do século XVIII, articularam o trabalho como um direito: nas palavras dos tecelões revoltosos na Lion de 1831, tratava-se de "viver trabalhando ou morrer combatendo" (RUSCHE; KIRCHHEIMER, 2004, p. 137). O contraste com os períodos anteriores é notável: depois de passar dois séculos sendo compelida ao trabalho, à base de decepamentos, açoites, enforcamentos e torturas as mais variadas, a população europeia - ou pelo menos parte dela - já tinha sido obrigada a afastar-se suficientemente das formas de vida anteriores à expropriação capitalista para entregar-se por sua própria conta, e por falta de opção histórica, ao trabalho assalariado. Sabemos como o formato do Estado de Direito moderno deve-se fundamentalmente à luta política ferrenha e persistente, articulada sobretudo em torno das organizações de trabalhadores.

O primeiro apogeu da expansão industrial na Europa, nas últimas décadas do século XIX, foi um contexto especialmente promissor para a atuação dessas organizações - o que, evidentemente, não significa que sua luta foi menos árdua: apenas, que suas conquistas foram economicamente mais viáveis. Foi também nesse período que o trabalho prisional alcançou seu ápice efêmero, tendo sido, aliás, tenazmente combatido pelos traba- 


\section{ADVistg all pavtg}

\} PARADIGMAS DE POLÍTICA PENAL E SENTIDO ECONÔMICO - OLIVEIRA, P. R. \}

DOI: $10.12957 /$ REP.2016.25402

Ihadores que lutavam por emprego fora das grades (O'BRIEN, 1998, p. 203-204; RUSCHE; KIRCHHEIMER, 2004, p. 185). De fato, parte desse combate envolvia uma radical dessolidarização de classe: as organizações de trabalhadores pressionaram de todas as formas possíveis para uma cisão no exército de mão de obra de reserva e contra a contratação de ex-prisioneiros por seus patrões. De qualquer modo, é discutível o quão lucrativo foram os esquemas de exploração direta do trabalho de prisioneiros ou mesmo de subcontratação de sua força de trabalho (RUSCHE; KIRCHHEIMER, 2004, p. 155).

Mas, novamente, condições especiais contribuíram para a intensificação dessas práticas: em especial, a demanda estatal proporcionada pela militarização europeia no início do século XX foi um fator importante na viabilização do trabalho prisional no período industrial, na medida em que fazia sentido contábil manter imobilizada uma população de trabalhadores produzindo uniformes, botas e peças de armamentos por meses a fio.

\section{As penas alternativas no pós-guerra}

Uma das tendências importantes da política penal da sociedade moderna foram as fianças e multas. Esses recursos punitivos empregados para marcar a diferenciação de status na antiga sociedade feudal - na qual o chicote era reservado para os camponeses e miseráveis - foram ressuscitados e propagandeados com despudorado entusiasmo, no século XVIII, pela burguesia revolucionária, em sua tentativa geral de racionalizar o sistema judiciário em termos quantitativos - aqui, sob a forma oportuna dos pagamentos em dinheiro que poderiam manter as classes proprietárias convenientemente afastadas das sanguinárias políticas penais modernas.

O século XIX assistiu a uma expansão e sofisticação considerável da aplicação das multas e fianças, especialmente a partir do aumento da demanda de força de trabalho - e, com isso, dos salários - nas décadas finais (MCCONVILLE, 1998, p. 161). Através da difusão ulterior da prática de suspensão de sentenças com a aplicação de alguma variedade de supervisão judicial, foi possível estender práticas de não encarceramento mesmo sobre as parcelas mais pobres da classe trabalhadora, o que funcionou no sentido da manutenção do exército industrial de reserva.

Essa tendência foi retomada e expandida nas décadas anteriores à Primeira Guerra (RUSCHE; KIRCHHEIMER, 2004, p. 203) e continuou a sê-lo depois da Segunda Guerra. Além do morticínio e da destruição de infraestrutura, a expansão econômica das chamadas "décadas douradas" do pós-guerra causou uma alta demanda de força de trabalho. A penologia científica, nascida no século XIX, sofreu uma inflexão terapêutica na direção da "reabilitação" do prisioneiro. Nos Estados Unidos, o sistema prisional 


\section{heVistg ent paUtg}

\} PARADIGMAS DE POLÍTICA PENAL E SENTIDO ECONÔMICO - OLIVEIRA, P. R.\}

DOI: $10.12957 /$ REP.2016.25402

adotou a audaz nomenclatura de "sistema correcional" em 1954. Aí, o movimento de direitos civis teve reflexos para os encarcerados, tanto através de uma série de rebeliões prisionais, quanto através de importantes precedentes estabelecidos por decisões judiciais de inspiração "liberal" (ROTMAN, 1998, p. 171-172).

Nesse contexto, na Europa, com a aplicação extensiva de penas alternativas, liberdade condicional e regimes abertos e semiabertos, alguns países experimentaram um decréscimo significativo da taxa de encarceramento - o que não aconteceu na Inglaterra, entretanto, onde a taxa de encarceramento continuou crescendo tenazmente (O'BRIEN, 1998, p. 199221). Mas, mesmo aí, foram perceptíveis os efeitos da expansão da liberdade condicional e das fianças. Embora tenha sido observado que o número de multas e fianças nunca chegou a alcançar uma porcentagem significativa dentro do número total de condenações criminais (JANKOVIC, 1977, p. 17), é importante observar que, ao longo do século $X X$, um número enorme de faltas simplesmente saiu da esfera penal, migrando para esferas administrativas, segundo a lógica da especialização judicial nos ramos trabalhista, familiar, comercial etc. Essa migração significou, no fim das contas, uma substantiva expansão das multas e fianças como política punitiva não criminal.

Nos EUA, o pós-guerra assistiu a uma estabilização e, posteriormente, a uma queda na taxa de encarceramento. Os 119 prisioneiros por 100.000 habitantes registrados em 1961 caem para 94 prisioneiros por 100.000 habitantes em 1968, com uma redução absoluta na população carcerária de cerca de 33.000 presos. As taxas de 1961 só foram alcançadas novamente em 1975 - ano que registrou um aumento até então inédito de mais de $10 \%$ na população carcerária (BJS, 1982, p. 2). Desde então, aumentos anuais dessa ordem tornaram-se coisa corriqueira.

\section{A política penal sob o neoliberalismo e a exclusão potencial de parte da população do mercado de trabalho}

Em 1975, os Estados Unidos contavam 380 mil pessoas atrás das grades. Em 1979, a taxa de encarceramento chegou a 137 presos por 100.000 habitantes - repetindo o auge anterior que havia sido atingido no ápice da Grande Depressão, em 193911. O número de encarcerados subiu para 500.000 detentos em 1980, chegou a 1 milhão de detentos em 1990, a 1,93 milhão em 2000 (WACQUANT, 2013, p. 203; VOGEL, 2003, p. 39) e 2,23 milhões em 2013, o que equivale a 716 detentos por 100.000 habitantes (WALMSLEY, 2013, p. 3). Os EUA possuem, hoje, a maior popu-

\footnotetext{
${ }_{1}^{1}$ Mesmo nos primeiros anos da Depressão, quando o número de encarcerados permaneceu estável, houve um aumento notável na severidade das penas (STERN, 1941).
} 


\section{ADVistg all PaUtg}

\} PARADIGMAS DE POLÍTICA PENAL E SENTIDO ECONÔMICO - OLIVEIRA, P. R. \}

DOI: $10.12957 /$ REP.2016.25402

lação carcerária do mundo, seguido por China, Rússia e Brasil, que tem cerca de 600 mil prisioneiros e uma taxa de encarceramento de 299 presos por 100.000 habitantes (DEPEN, 2014, p. 12). À guisa de comparação, a taxa de encarceramento na Alemanha nazista, em 1938, incluindo os mantidos nos campos de concentração, ficava em torno de 162 presos por 100.000 habitantes ${ }^{2}$.

O brutal crescimento no encarceramento, a partir de meados da década de 1970, marca, em geral, os países ocidentais. Ao estudar esse fenômeno, no início do século XXI, Loïc Wacquant (2013, p. 12) associouo ao conjunto de transformações político-econômicas comumente referido através do termo "neoliberalismo": o desmonte do Estado de Bem-Estar construído nas "décadas de ouro" do pós-guerra; a erosão do trabalho estável através da contínua "reestruturação produtiva" (WACQUANT, 2013, p. 106); a abordagem governamental de segregação social levada a cabo, entre outros meios, pelo encarceramento em massa e aumento colossal da supervisão judicial. Wacquant trabalha sobretudo com análises dos EUA e da França, mas, se lermos seu trabalho sem perder de vista a questão do sentido econômico da população, podemos extrair apontamentos de impacto mais geral na interpretação do capitalismo contemporâneo.

A lógica social que Wacquant apresenta envolve, para começar, uma transformação clara no perfil da ação estatal junto a um setor específico da classe trabalhadora: aquele que é tradicionalmente o beneficiário dos programas de bem-estar social. De fato, o autor traça um convincente paralelo entre levantamentos do perfil socioeconômico dos beneficiários das políticas de compensação social - sobretudo, esquemas federais de ajuda financeira - e os alvos do sistema carcerário e de tutela judicial. Para vários indicadores de fragilidade socioeconômica - baixa renda, baixa educação formal, saúde deteriorada, uso de drogas, experiência social da violência etc. - aqueles perfis são virtualmente idênticos (WACQUANT, 2013, p. 46, p. 178).

Contudo, a coincidência não se dá apenas no contorno sociológico: trata-se, no fim das contas, do mesmo conjunto gigantesco de pessoas. Uma integração paulatina entre os cadastros informatizados dos serviços de compensação social e aqueles do sistema carcerário e de tutela judicial, a qual acompanhou a paulatina retração das políticas sociais a partir da década de 1980, sedimentou burocraticamente uma população de pobres puníveis (WACQUANT, 2013, p. 56-57). Ao mesmo tempo que os cadastros dos punidos e dos beneficiados foram integrados, uma alteração no perfil do esquema de auxílio financeiro governamental, que teve lugar na década de 1990, inseriu procedimentos de controle medonhos, que tornaram a manutenção do beneficiamento semelhante à submissão aos esquemas punitivos de tutela judicial ou liberdade condicional. A per-

${ }^{2}$ Número computado a partir de Rusche e Kirchheimer (2004, p. 259) e Evans (2005, p. 90). 
manência nos programas de auxílio está condicionada, hoje, a uma série de quesitos tais como a busca contínua de (sub)emprego, o não nascimento de filhos, a permanência na casa dos pais e a frequência em cursos de capacitação (WACQUANT, 2013, p. 151, p. 158, p. 183). A multiplicação de escritórios de supervisão de beneficiários a nível municipal, muitas vezes ligados a ONGs (WACQUANT, 2013, p. 186-188), possibilitam que, ao mesmo tempo que confere auxílio financeiro aos mais pobres, o Estado monitore e administre diretamente a vida de 1,7 milhão de indivíduos em sua maioria, jovens - e, indiretamente, a de suas famílias, chegando a um total de 4,2 milhões de pessoas (FALK, 2015, p. 3) cuja conduta econômica, social e sexual é supervisionada.

É importante ter em conta que um sentido fundamental da complementação de renda através da atuação do Estado - de forma semelhante ao que acontece no Brasil com o Bolsa Família e outros auxílios condicionados, ou em diversos outros países com esquemas semelhantes - é tornar viável a manutenção sistemática de uma força de trabalho remunerada abaixo do mínimo necessário à subsistência, ou que exerce atividade de trabalho apenas esporadicamente. Esse é o perfil da maior parte dos empregados no mundo de hoje, de acordo com o a Organização Internacional do Trabalho (ILO, 2015, p. 30).

O Brasil definitivamente não escapa a essa regra, conforme atestam os altos números da rotatividade do emprego ${ }^{3}$ e da informalidade ${ }^{4}$. Tampouco escapam os EUA, que têm uma taxa de ocupação semelhante à brasileira ${ }^{5}$, e onde cerca de $38 \%$ da população teve alguma experiência com o desemprego, seja em sua própria família, seja em famílias próximas, entre meados dos anos 1990 e início dos 2000. Hoje, o maior empregador da maior economia do mundo é a Manpower Incorporated: uma empresa que terceiriza a contratação de mão de obra precária e temporária (WACQUANT, 2013, p. 108, p. 106).

Tudo isso conspira para um quadro de normalização da insegurança econômica no capitalismo contemporâneo e, portanto, dá indicações fortes sobre o sentido econômico da população, influenciando a política penal e enraizando a onda de encarceramento e de extensão da tutela judicial no regime de acumulação capitalista.

É preciso frisar, entretanto, que não se trata de aceitar o mecanismo simplório da criminologia tradicional, segundo o qual a insegurança econômica ou o desemprego geram um aumento da criminalidade entre

\footnotetext{
${ }^{3}$ A rotatividade do mercado de trabalho brasileiro está entre as maiores do mundo. Trata-se de uma relação entre contratações e demissões que espelha a curta duração e a instabilidade do trabalho (DIEESE, [2012]. p. 2-5).

${ }^{4}$ Cerca de $29,8 \%$ da população entre 15 e 64 anos aparece como economicamente inativa no censo de 2010 . Esses dados foram obtidos a partir de tabelas do Sistema IBGE de Recuperação Automática (SIDRA), Censo Demográfico 2010 (IBGE, 2010). Segundo dados da OECD (2015d), essa taxa teria chegado a 32,3\% em 2013. O autor gostaria de agradecer a Wagner Soares pela prestimosa ajuda com os bancos de dados do IBGE.

${ }^{5}$ A taxa de participação na força de trabalho dos EUA está em torno de $62 \%$ (BLS, 2015. p. 11). Considerando uma taxa de desemprego de $6,7 \%$ para o Brasil (IBGE 2010), as taxas de participação na força de trabalho seriam quase idênticas para os dois países.
} 


\section{ADVistg all PaUtg}

\} PARADIGMAS DE POLÍTICA PENAL E SENTIDO ECONÔMICO - OLIVEIRA, P. R. \}

DOI: $10.12957 /$ REP.2016.25402

as populações precariamente inseridas no mercado de trabalho, aumento este que, por sua vez, geraria uma resposta governamental sob a forma de uma política penal mais dura. Parece razoável supor que a necessidade material extrema deve ser a origem de grande parte dos crimes contra a propriedade; entretanto, se concordamos com as teses fundamentais da criminologia crítica de inspiração materialista apresentadas e defendidas até aqui, é simplesmente falso que a rigidez penal deriva de um aumento da criminalidade. Como vimos, sua origem não é a criminalidade, mas o sentido econômico da população. De fato, estudos estatísticos para os EUA e a Europa mostram que o aumento da taxa de encarceramento não acompanha um aumento na ocorrência de crimes. Para os principais índices relacionados a crimes contra a propriedade (invasões, roubos qualificados etc.), as épocas recentes mostram que o aumento cavalar do encarceramento não acompanha aumentos das taxas criminais. Na realidade, o que responde por tal aumento são as prisões por crimes relacionados a drogas: a tal "guerra às drogas" proclamada por Ronald Reagan em 1981 e por diversos outros representantes do poder executivo pelo mundo afora (WACQUANT, 2013, p. 212-213, p. 222, p. 115-116).

Para entender a guerra às drogas de forma crítica, contudo, não basta introduzi-la na discussão sob a forma de uma resposta a algum suposto aumento da prática de crimes relacionados a drogas: na medida em que as políticas penais são respostas ao problema da alteração do sentido econômico da população, é preciso enraizá-la no quadro geral do regime de acumulação contemporâneo. Para início de conversa, o trabalho no "comércio varejista de drogas ilícitas" (BRITO, 2013, p. 79) tem que ser entendido como uma faceta da atividade econômica rentável no mundo do trabalho precário e irregular e da economia informal (WACQUANT, 2013, p. 115). Assim, antes de ser uma resposta ao "crime organizado" ou às "violências urbanas" (WACQUANT, 2013, p. 64), a guerra às drogas consiste na ação governamental - sob a forma do confronto armado, do encarceramento e da tutela judicial - junto a uma determina parcela da população: os pobres puníveis que vivem além das margens da economia formal. Na medida em que - nos EUA, na França, no Brasil e em toda parte - essa população, através das décadas, foi economicamente segregada para áreas específicas das cidades, aquela ação governamental armada e punitiva tem expressão territorial.

A segregação econômico-territorial tem, ademais, um nítido corte étnico em grande parte das sociedades ocidentais, reflexo tardio do já antigo imperialismo europeu dos séculos XVI e XIX, fixado pela rigidez econômica da sociedade do trabalho assalariado. Nos EUA, isso se expressa em números assustadores. Em 1993, a taxa de encarceramento de negros era de 1.895 prisioneiros para cada 100.000 habitantes, contra 293 brancos para 100.000 habitantes (WACQUANT, 2013, p. 114). Em 2001, aquela taxa, para negros do sexo masculino, chegou a 3.535 presos por 100.000 ha- 


\section{heVistg ent paUtg}

\} PARADIGMAS DE POLÍTICA PENAL E SENTIDO ECONÔMICO - OLIVEIRA, P. R.\}

DOI: $10.12957 /$ REP.2016.25402

bitantes, contra 462 por 100.000 para homens brancos (HARRISON; BECK, 2002, p. 12). Em 2009, 4,7\% de toda a população de negros adultos estava atrás das grades (WEST, 2010, p. 22). Segundo dados recentes, "um a cada três americanos negros nascidos [em 2013] podem esperar ser encarcerados durante sua vida" (TSP, 2013, p. 1).

Quando se leva em conta a tutela judicial, os números são ainda mais terríveis. Em 1990, no estado da Califórnia, cerca de $40 \%$ dos afroamericanos entre 18 e 35 anos estavam encarcerados ou sob liberdade vigiada, enquanto que, na cidade de Washington D.C., essa porcentagem chegava a $42 \%$ e, em Baltimore, a 56\% (WACQUANT, 2013, p. 118). Diversos estados americanos privam de direitos políticos os ex-condenados (por certos crimes) ou indivíduos sob supervisão judicial. O resultado disso é que, no início dos anos 2000, 14\% do eleitorado afro-americano estava impedido de votar (WACQUANT, 2013, p. 312).

Levando em conta a população total, em 2013, a cada 51 adultos americanos, um estava sob tutela judicial (HERBERMAN, BONCZAR, 2015, p. 1). A rotação carcerária e tutelar, incluindo a de menores (a maioria dos quais são negros, diga-se de passagem), é tão grande que, no início dos anos 2000, mais de 30 milhões de cidadãos americanos tinham ficha criminal, o que equivalia, então, a cerca de $1 / 3$ da população adulta masculina (WACQUANT, 2013, p. 234).

É preciso atentar para o significado desse último dado. Ter ficha criminal não é uma questão menor para uma população que experimenta dificuldades crescentes em encontrar trabalho, num país em que a insegurança econômica generalizada junta-se com lobbies sindicais, ideologia punitivista de classe média e uma tecnologia de informação abundante e barata. Existem hoje, nos EUA, cerca de 600 empresas de "background check", ou seja, empresas de "consultoria" que vendem os antecedentes criminais de possíveis empregados para seus possíveis empregadores (WACQUANT, 2013, p. 240). Isso significa que existem hoje milhões de pessoas nos EUA que, devido ao estigma da condenação penal, estão potencialmente impedidas de participar do mercado de trabalho. Levando em conta apenas os encarcerados e os tutelados, esse número chega a 7 milhões, ou cerca de 3\% da população adulta. Entretanto, tendo em vista a quantidade de fichas criminais circulantes e publicamente disponíveis no país, o número concreto de pessoas que vivem sob o estigma da não empregabilidade e, portanto, estão potencialmente excluídas do mercado de trabalho deve ser muito maior ${ }^{6}$.

\footnotetext{
${ }^{6}$ Uma série de estudos sugere que essa exclusão é muito mais que potencial (MILLER, 1972; PAGER, 2003; LAM; HARCOURT, 2003; WESTERN, 2008).
} 


\section{A abordagem territorial da exclusão populacional seletiva}

Essa exclusão potencial é um dado fundamental. A política penal nos EUA aponta para um retorno da abordagem estatal de seletiva eliminação populacional. Essa eliminação se verifica mesmo quando deixamos de lado fenômenos importantes, tais como as epidemias de doenças infectocontagiosas que há décadas afetam o sistema prisional norte-americano (MORRIS, 1998, p. 222-224), o número alarmante de mortos e feridos em brigas e conflitos diários com a polícia carcerária (WACQUANT, 2013, p. 251252) ou as macabras cifras da vitimação letal por ação da polícia nas ruas.

Chama atenção, ademais, que o caso dos EUA, embora extremo, não é isolado. Nos últimos 15 anos, enquanto a população mundial aumentou $20 \%$, a taxa de encarceramento mundial cresceu entre 25 e $30 \%$, subindo de cerca de 136 presos por 100.000 habitantes para cerca de 144 presos por 100.000 habitantes (WALMSLEY, 2013, p. 1). Da mesma forma, há várias indicações de que a aplicação de formas punitivas que envolvem a administração populacional através da tutela judicial - as quais não entram nas estatísticas de aprisionamento - estão também em expansão. Finalmente, em paralelo a tudo isso, desenvolvem-se esquemas de policiamento intensivo que primam por uma administração armada de uma população não encarcerada, a partir de uma abordagem territorial que delimita regiões urbanas especialmente policiáveis e policiadas com tal intensidade que o cotidiano pode ser descrito como a contínua aplicação de uma política penal. Esse fenômeno precisa ser mapeado para que o sentido econômico da população na contemporaneidade - na medida em que ele aparece através da política penal - seja satisfatoriamente decifrado.

Três exemplos paradigmáticos são especialmente significativos para a compreensão da administração territorial armada. Em primeiro lugar, vimos como, nos EUA, a retração dos esquemas de compensação social e a deterioração do emprego estável combinou-se a uma política de encarceramento e tutela judicial expansivos. A ponta de lança dessa política é uma espécie de proatividade policial no que diz respeito à atuação nas áreas urbanas habitadas pela população economicamente fragilizada: os bairros de negros pobres.

E importante levar a sério a caracterização da atuação policial como proativa: nessas áreas, a polícia não atua respondendo a chamados emergenciais, mas adianta-se às queixas, promovendo detenções periódicas e sistemáticas. É assim que, por exemplo, a partir do final da década de 1990, com a justificativa de uma "atuação preventiva", a polícia de Nova lorque começou a realizar um número maior de detenções do que o de denúncias recebidas (WACQUANT, 2013, p. 435). Com a mesma justificativa, várias cidades norte-americanas, a partir do início dos anos 1990, instituíram toques de recolher - por exemplo, para menores de 16 anos depois das 10:30 da noite, e daí por diante - especialmente nos bairros 


\section{heVistg ent paUtg}

\} PARADIGMAS DE POLÍTICA PENAL E SENTIDO ECONÔMICO - OLIVEIRA, P. R.\}

DOI: $10.12957 /$ REP.2016.25402

pobres e em seus arredores. No entanto, tal medida supostamente "preventiva" não diminuiu, mas aumentou o número de detenções (WACQUANT, 2013 , p. 124) - as quais, ademais, em geral já atingem, em sua esmagadora maioria, a juventude negra e pobre.

Em segundo lugar, as Zonas Urbanas Sensíveis (ZUS) - atualmente denominadas Bairros Prioritários - foram delimitadas em 1996 pelo governo francês como parte de uma programada "renovação urbana". Definidas em termos da pobreza de seus habitantes e da precariedade dos serviços urbanos disponíveis, essas zonas abrigam cerca de $7 \%$ da população fran$\mathrm{cesa}^{7}$. A política de policiamento intensivo e proativo ali empregada sistematicamente detonou os motins urbanos que se espalharam pela França em 2005.

O terceiro exemplo é o da política de ocupação e administração territorial armada empreendida no estado do Rio de Janeiro através do programa de Unidades de Polícia Pacificadora (UPPs), inaugurado em 2008. Nas comunidades com UPP, a atuação policial rotineira inclui checkpoints, revistas aleatórias e invasões a domicílios (O DIA, 2013). Assassinatos, agressões e torturas perpetrados por policiais são cotidianos (ANISTIA INTERNACIONAL, 2015, p. 26-28, p. 70, p. 75); alguns chegam à grande mídia sem exercer qualquer impacto na política de segurança pública, mas reafirmando, para quem quiser ver, a normalização e oficialização da violência policial -, enquanto tantos outros permanecem do conhecimento apenas de suas vítimas, às quais a ubíqua presença policial impõe um temeroso silêncio (ANISTIA INTERNACIONAL, 2015, p. 76).

Levantes populares contra a atuação abusiva da polícia também são constantes (EXTRA, 2014; SCHOTT, 2015), e não raro desencadeiam novas violências. Sem realmente evitar confrontos com grupos que empreendem o comércio varejista de drogas a partir das comunidades (HERINGER et al., 2013; MARTINS; BRITO, 2014) - estando aí a justificativa inicial do programa - as UPPs instalam um regime de violência estatal cotidiana que, nessa medida, representa um caso da desgraçada regra geral que parece desde sempre reger a relação entre o Estado e os pobres na periferia do capitalismo. Contudo, segundo cremos, as UPPs inserem uma inflexão específica nessa relação, na medida em que consolidam oficialmente uma dimensão territorial às rondas rotineiras e constantes de extermínio e intimidação dos pobres perpetradas pela polícia carioca até então.

Para entender essa inflexão é preciso levar em conta a enorme densidade policial a que as comunidades com UPPs estão submetidas. Enquanto a média mundial fica em torno de um policial para cada 292 habitantes (HERRENDORF; HEISKANEN; MALBY, 2010, p. 136), o estado

${ }^{7}$ Segundo dados disponibilizados em 2010 pelo Instituto Nacional de Estatística e Estudos Econômicos da França (INSEE, 2010). 


\section{ADVistg all PaUtg}

\} PARADIGMAS DE POLÍTICA PENAL E SENTIDO ECONÔMICO - OLIVEIRA, P. R. \}

DOI: 10.12957/REP.2016.25402

do Rio de Janeiro tem em torno de um policial militar para cada 268 habitantes $^{8}$, e cidades como Nova lorque e Washington D.C. contam com, respectivamente, um policial para cada 246 habitantes e um policial para cada 163 habitantes (REAVES, 2015, p. 14), já a média nas comunidades com UPP é de um policial para cada 62 habitantes ${ }^{9}$. Em mais da metade dessas comunidades, essa relação é maior do que um policial para cada 50 habitantes. Quando levamos em conta a densidade espacial, os números são ainda mais destoantes. Para repetir a comparação com as cidades norteamericanas, tradicionalmente vistas como "bem policiadas": enquanto Washington D.C. conta com 22 policiais por quilômetro quadrado e, em Nova lorque, esse número chega a 29 policiais por quilômetro quadrado, nas comunidades com UPP a média é de 989 policiais por quilômetro quadrado ${ }^{10}$.

Será possível ler essa gigantesca densidade policial em termos das alegadas necessidades do chamado "combate ao crime"? Embora o poder público do Rio de Janeiro continuamente alardeie estatísticas de redução criminal - ao mesmo tempo em que a mídia bombardeia a população com reiteradas "denúncias" de "abusos" policiais, cuja cotidianidade só tem efeito intimidador - o histórico de violência contínua nas comunidades atesta apenas por uma regularização do conflito armado - no qual, aliás, perece um policial a cada 40 dias (COELHO, 2015). De fato, esse histórico não escapa aos ciosos administradores das ações armadas cotidianas em territórios urbanos, entre os quais tornaram-se comuns declarações no sentido de que é impossível derrotar "o crime" ou "o tráfico de droga" através das armas (AQUINO, 2015) ${ }^{11}$ - o que, de todo modo, não os impede de persistir em sua abordagem militarizada, obviamente com respaldo governamental. Isto sugere uma macabra generalização da consciência de que não se trata de combater o crime, mas de algo que só pode ser descrito como uma guerra permanente contra os pobres.

É preciso entender essa descrição independentemente de seu efeito bombástico e escandaloso, mas como caracterização precisa da política penal contemporânea. É evidentemente problemático empregar a categoria da guerra para descrever operações armadas de caráter cotidiano em territórios urbanos no interior de um bem definido Estado nacional ${ }^{12}$. No en-

\footnotetext{
${ }^{8}$ Segundo regulado pela Lei no 6681 de 15 de janeiro de 2014 (RIO DE JANEIRO, 2014).

${ }^{9}$ Esse número foi obtido com base nas estimativas populacionais para as comunidades abrangidas por cada UPP reunidas pelo Instituto Pereira Passos (2010a) e os efetivos policiais de cada UPP (GOVERNO DO ESTADO DO RIO DE JANEIRO, s/d). Acesso em setembro de 2015. Para efeitos de comparação: numa das maiores penitenciárias dos EUA, a Twin Towers Correction Facility, em Los Angeles, trabalha um guarda para cada quatro detentos (WACQUANT, 2013, p. 252).

${ }^{10}$ Esse número foi obtido a partir do total das áreas das comunidades abrangidas pelas UPPs e do efetivo total de cada UPP. A listagem das áreas das comunidades e os efetivos foram extraídos do sítio oficial do programa (GOVERNO DO ESTADO DO RIO DE JANEIRO, s/d). As áreas das comunidades foram extraídas do sítio do Instituto Pereira Passos (2010b).

${ }^{11}$ Conclusão semelhante foi extraída de pesquisa realizada com delegados de polícia nos EUA nos anos 1990 (WACQUANT, 2013, p. 117).

${ }^{12}$ Os paradoxos do emprego do conceito de guerra para descrever as operações armadas cotidianas desencadeadas nos espaços de pobreza são discutidos em Brito, Villar e Blank (2013).
} 


\section{heVistg ent paUtg}

\} PARADIGMAS DE POLÍTICA PENAL E SENTIDO ECONÔMICO - OLIVEIRA, P. R.\}

DOI: $10.12957 /$ REP.2016.25402

tanto, a intensidade e o caráter dos conflitos permanentes desencadeados pelas UPPs e abordagens territoriais semelhantes carrega características de guerra de ocupação. Em 2003, lobistas da ocupação do Iraque, reclamando aumento da presença militar norte-americana no país, projetavam que, para uma "estabilização sustentável", seria necessária uma taxa mínima de um soldado por 50 habitantes (QUINLIVAN, 2003) - algo próximo da densidade soldadesca empregada nas ocupações do Kosovo (1999) e da Bósnia (1996), mas ultrapassada por mais da metade das comunidades com UPP! A arquitetura das UPPs também tem algo a revelar sobre seu caráter de ocupação militar: a reforma da sede da Polícia Pacificadora no Complexo do Alemão, na Praça Cruzeiro, substituiu o contêiner original por um bunker quadrado sem janelas, mas provido de orifícios estratégicos para apoio de fuzis (FANTTI, 2015).

Contudo, o traço fundamental da abordagem penal territorial que contribui para a decifração do sentido econômico da população na contemporaneidade é seu caráter misto de discriminação e não discriminação. Na medida em que é política penal, a abordagem territorial projeta uma população de criminosos ou, pelo menos, de suspeitos. Isso ficou literalmente registrado em um mandado de busca e apreensão emitido por um juiz autorizando a entrada da polícia em todas as residências de duas comunidades do Complexo da Maré, no Rio de Janeiro (SOARES, 2014). Ademais, a abordagem policial cotidiana - o ser parado pelo policial várias vezes durante uma noite no fim de semana para ter seus pertences revistados; a circulação na área de residência sob o olhar constante de oficiais armados - impõe à comunidade um regime disciplinar evocativo das revistas de celas e contagens de internos que marcam o dia a dia numa penitenciária.

Uma vez que essa população de criminosos ou suspeitos está invariavelmente localizada nos espaços de pobreza - as favelas e bairros pobres, com baixíssima densidade de infraestrutura e serviços urbanos -, a política penal territorial é discriminatória. Por outro lado, porquanto subentendase que, entre a população dos espaços de pobreza, existem criminosos e não criminosos, ao mesmo tempo em que submete todos ao mesmo tratamento de cunho materialmente punitivo, a abordagem penal territorial é não discriminatória, tratando com indiferença inocentes e culpados.

Entre a população carioca, o caráter misto de discriminação e não discriminação envolvido na operação das UPPs aparece na fala perplexa que reclama dos "abusos" da polícia dizendo: "aqui na favela também tem trabalhador!" De fato, com base no último censo do IBGE, é possível determinar que cerca de $10,5 \%$ da população economicamente ativa do Rio de Janeiro vive, hoje, nas áreas ocupadas por UPPs ${ }^{13}$ : uma cifra nada desprezível. No entanto, através da administração armada dos territórios,

\footnotetext{
${ }^{13}$ Esse número foi obtido a partir de dados do censo IBGE (2010) para aglomerados subnormais, donde obtivemos uma média de atividade econômica para a população de favelas e estimativas populacionais do Instituo Pereira Passos
} 


\section{ADVistg all PaUtg}

\} PARADIGMAS DE POLÍTICA PENAL E SENTIDO ECONÔMICO - OLIVEIRA, P. R. \}

DOI: $10.12957 /$ REP.2016.25402

essa população é, cotidianamente, potencialmente impedida de exercer sua atividade econômica. Ou seja, seu sentido econômico é semelhante ao da população estadunidense que se encontra potencialmente excluída do mercado de trabalho ${ }^{14}$. Seja por serem feridos ou mortos pelo equipamento militar-policial (intencionalmente ou não), seja porque a reprodução da força de trabalho é regularmente obstaculizada pelo fechamento periódico das escolas e do comércio (ARAÚJO, 2015), seja, ainda, porque a intimidação e a contínua averiguação policial prejudicam indelevelmente sua mobilidade, para não falar de seu bem-estar físico e psíquico: essa população de trabalhadores assalariados e agentes econômicos independentes, formais e informais, é, na prática, administrada através das armas como se fosse quantitativamente indiferente.

Em outros termos, tal população, a um só turno, foi e não foi socializada através do trabalho e da atividade econômica. Ao longo dos séculos, ela foi definitivamente afastada de qualquer possibilidade de se manter existindo independentemente dos processos produtivos capitalistas - algo que se completa hoje quando as comunidades com UPPs, sofrendo intenso processo de gentrificação (OST; FLEURY, 2013; RODRIGUES, 2014), absorvem como parte do mercado regular de imóveis as habitações até então produzidas através de relações informais de cooperação na lógica da autoconstrução (MARICATO, 1979). No entanto, embora subsumida pelo mercado e pelo trabalho - com salários baixos, emprego altamente instável e rotativo, bem como relações jurídicas frouxas - tal população não adentra a cidadania plena.

Num país com enorme desigualdade econômica, contínua imigração interna, grande oferta e baixo preço de força de trabalho, isso sempre aconteceu: da "fronteira agrícola" dominada por coronéis no século XVIII às favelas cotidianamente submetidas ao terror policial do século XXI (OLIVEIRA, 2008, p. 43, p. 131), os espaços de pobreza sempre constituíram peça-chave no capitalismo brasileiro e sempre foram espaços de violência oficiosa. Exposta à truculência das "autoridades" ou trancafiada em prisões tradicionalmente insalubres e superlotadas, sempre houve uma população tratada como supérflua. Com as UPPs, entretanto, aquela violência oficiosa atinge a maturidade de uma política regular, intensa, oficial, com orçamento próprio e eleitoralmente sacramentada - política essa, ademais, que é expressão de uma guinada global na direção da criminalização territorial dos pobres.

É preciso observar que essa política penal que hoje trata a população como numericamente indiferente tem sentido distinto daquela que, no início da modernidade, promovia um extermínio consistente dos pobres e vagabundos. Ali, a população sem-habilidades era inequivocamente percebida e tratada pelo Estado como sobrante: por um lado, devido à sua in-

${ }^{14}$ Ver final da seção 6, acima. 


\section{heVistg ent paUtg}

\} PARADIGMAS DE POLÍTICA PENAL E SENTIDO ECONÔMICO - OLIVEIRA, P. R.\}

DOI: $10.12957 / R E P .2016 .25402$

capacidade cultural de participar do trabalho assalariado; por outro, devido à incapacidade do mercado de trabalho de absorvê-la. A partir do advento da prisão, da generalização da produção de mercadorias e da conversão da população em trabalhadores assalariados em potencial, a superpopulação passa a ser uma superpopulação relativa a um determinado momento do ciclo econômico capitalista: um momento sempre efêmero, em que a demanda por força de trabalho é pequena demais, deixando de fora da socialização através do dinheiro uma parte grande da população de trabalhadores. O desenvolvimento dos regimes prisionais de "correção", com programas médicos e profissionalizantes visando à reinserção do preso no mercado de trabalho, equivalem a épocas em que o estatuto de semhabilidade do preso deve ser a todo custo ultrapassado para que ele possa vender sua força de trabalho num quadro de alta demanda.

Isso corresponde a um período de expansão das relações sociais capitalistas através da expansão da industrialização. Aí, saltava aos olhos a perspectiva de socialização através do trabalho, e isso mesmo nos períodos de baixa demanda, como nos faz ver a supracitada fala dos tecelões de Lion. Tratava-se de "morrer combatendo" para "viver trabalhando" porque, através do trabalho, as populações que vinham sendo expropriadas desde um tempo histórico ainda recente poderiam inserir-se na civilização capitalista; alcançariam, através do dinheiro, suas benesses específicas que substituíam aquelas da lida direta com a natureza na sociedade agrária de subsistência.

No capitalismo industrial avançado e altamente financeirizado de hoje, é essa perspectiva civilizatória do trabalho que desaparece do horizonte e é enterrada sob a pá de cal da política penal territorial. A intensificação ininterrupta da expansão das relações capitalistas de manutenção da vida está combinada a uma contínua expansão do trabalho precário e esporádico. A população envolvida nessa expansão é a mesma que ora se torna alvo da política penal territorial e que, portanto, desde o ponto de vista da administração armada estatal da pobreza, é numericamente contingente.

Essa forma ingrata de socialização pelo trabalho se manifesta na fala do governador do Rio de Janeiro, emitida no final de agosto de 2015, aprovando e recomendado operações policiais que interrompem a viagem de ônibus que, originários de espaços de pobreza, têm como destino as praias turísticas da Zona Sul carioca (BARREIRA; COELHO, 2015). O estatuto econômico dos negros desembarcados dos ônibus e impedidos de chegar à praia - serão trabalhadores? - é, desde o ponto de vista da administração pública, indiferente. 


\section{ReVistg all paUtg}

\} PARADIGMAS DE POLÍTICA PENAL E SENTIDO ECONÔMICO - OLIVEIRA, P. R. \}

DOI: $10.12957 /$ REP.2016.25402

\section{Referências}

ANISTIA INTERNACIONAL. Você matou meu filho! Homicídios cometidos pela polícia militar na cidade do Rio de Janeiro. Rio de Janeiro: Anistia Internacional. 2015.

$A Q U I N O, R$. de. José Mariano Beltrame: a guerra às drogas é perdida, irracional. Extra, 26 jun. 2015. Disponível em: <http://goo.gl/0OHybj>. Acesso em: 1 set. 2015.

ARAÚJO, F. Violência deixou 32 mil alunos sem aula em 22 dias. O Dia, 19 ago. 2015. Disponível em: <http://goo.gl/ycsX2B>. Acesso em: set. 2015.

BARREIRA, G.; COELHO, H. Pezão defende PM após apreensão de menores a caminho de praia no RJ. G1, 24 ago. 2015. Disponível em: <http://goo.gl/ Fhvf1z>. Acesso em: 1 set. 2015.

BRITO, F.: Considerações sobre a regulação armada de territórios cariocas". In: BRITO, F.; ROCHA DE OLIVEIRA, P. (Org.). Até o último homem: visões cariocas da administração armada da vida social. São Paulo: Boitempo. 2013.

BRITO, F.; VILLAR, A.; BLANK, J. Será guerra? In: BRITO, F.; ROCHA DE OLIVEIRA, Pedro. (Org.). Até o último homem: visões cariocas da administração armada da vida social. São Paulo: Boitempo. 2013.

BJS. Bureau of Justice Statistics. Prisoners 1925-1981. Washington D.C.: U.S. Department of Justice. 1982.

BLS. Bureau of Labor Statistics. The employment situation (July 2015). Washington DC: U.S. Department of Labor. 2015.

COELHO, H. Um policial morre a cada 40 dias em UPPs do Rio desde 2014. G1, 9 jul. 2015. Disponível em: <http://goo.gl/gtVRt0>. Acesso em: 1 set. 2015.

DEPEN. Departamento Penitenciário Nacional. Levantamento nacional de informações penitenciárias Infopen (junho de 2014). Brasília: Ministério da Justiça. 2014.

DIEESE. Os números da rotatividade no Brasil. Um olhar sobre os dados da Rais (2002-2012). São Paulo: Dieese. [2012].

EVANS, R. The Third Reich in power. London: Penguin Books. 2005.

EXTRA. Policiais da UPP Camarista Méier são atacados com pedras e paus. Extra, 26 maio. 2014. Disponível em: <http://goo.gl/MwNm2G>. Acesso em: 1 set. 2015.

FALK, G. The Temporary Assistance for Needy Families (TANF) block grant: responses to frequently asked questions. Washington DC: Congressional Research Service. 2015. 


\section{heVistg ent paUtg}

\} PARADIGMAS DE POLÍTICA PENAL E SENTIDO ECONÔMICO - OLIVEIRA, P. R. \}

DOI: $10.12957 /$ REP.2016.25402

FANTTI, B. UPP no Alemão troca contêiner por bunker com buracos para apoiar fuzil. Folha de São Paulo, 12 ago. 2015. Disponível em: <http:// folha.com/no1667530>. Acesso em: 1 set. 2015.

GOVERNO DO ESTADO DO RIO DE JANEIRO. UPP - Unidade Policial Pacificadora. S/D. Disponível em: <http://www.upprj.com/>. Acesso em: 1.set.95.

HERRENDORF, S.; HEISKANEN, M.; MALBY, S. International statistics on crime and justice. Helsinki: European Institute for Crime Prevention and Control. 2010.

HARRISON, P. M.; BECK, A. J. Prisoners in 2001. Bureau of justice statistics bulletin. Washington DC: U.S. Department of Justice. 2002.

HERBERMAN, E. J.; BONCZAR, T. P. Probation and parole in the United States (2013). Washginton DC: Bureau of Justice Statistics. 2015.

HERINGER, C. et al. Tráfico retoma pela primeira vez área em favela com UPP em comunidade de Copacabana. Extra, 10 nov. 2013. Disponível em: <http://goo.gl/kOKplZ>. Acesso em: 1 set. 2015.

$\mathrm{HILL}, \mathrm{C}$. Intellectual origins of the English Revolution. Oxford: Clarendon Press. 1980.

IBGE. Instituto Brasileiro de Geografia e Estatística. "Tabela 3991 - Pessoas de 10 anos ou mais de idade, por idade, condição de atividade e de ocupação na semana de referência e tipo do setor - Resultados Gerais da Amostra." In: Banco de Dados Agregado. 2010. Disponível em: < http://www.sidra. ibge.gov.br/ bda/tabela/listabl.asp?z=cd\&o=19\&i=P\&c=3991 >. Acesso em: 1.set.2015.

ILO. International Labour Office. World employment and social outlook 2015: the changing nature of jobs. Geneva: ILO. 2015.

INSTITUTO PEREIRA PASSOS. "Tabela 3402 - População e número de domicílios particulares permanentes segundo as favelas e comunidades em complexos cadastradas - Município do Rio de Janeiro". In: Armazém de Dados. 2010a. Disponível em: <http://www.armazemdedados.rio.rj.gov.br/ arquivos/3402_pop_dom_favelas_2010.XLS>. Acesso em: 1.set.95.

INSTITUTO PEREIRA PASSOS. "Tabela 2642 - Área ocupada pelas comunidades cadastradas segundo as Áreas de Planejamento e Regiões Administrativas - Município do Rio de Janeiro - 2004/2013." In: Armazém de Dados. 2010b. Disponível em: < http://www.armazemdedados.rio.rj.gov.br/ arquivos $/ 2642$ \%C3\%A1 rea\%20ocupada\%20pelas $\% 20$ favelas $\% 20$ ca dastradas\%20segundos\%20aps_ras_04_13.XLS>, Acesso em: 1.set.95.

INSEE. Institut national de la statisque et des études économiques. "La population des zones urbaines sensibles". In: Insee Première, 1328. Dezembro de 2010. Disponível em: <http://www.insee.fr/fr/themes/document.asp?id $=3131 \&$ reg_id=0 $>$. Acesso em 1.set.2015. 


\section{ApVistg all paUtg}

\} PARADIGMAS DE POLÍTICA PENAL E SENTIDO ECONÔMICO - OLIVEIRA, P. R. \}

DOI: 10.12957/REP.2016.25402

JANKOVIC, I: Labor market and imprisonment. Crime and Social Justice, n. 8. 1977.

LAM, H.; HARCOURT, M. The use of criminal records in employment decisions: the rights of ex-offenders, employers and the public. Journal of Business Ethics, v. 47, n. 3, out. 2003.

LINEBAUGH, P.; REDIKER, M. The many-headed hydra. Boston: Bacon Press. 2011.

MARICATO, E. Autoconstrução, a arquitetura possível. In: MARICATO, E.; OLIVEIRA, F. de. (Org.). A produção capitalista da casa (e da cidade) no Brasil industrial. São Paulo: Editora Alfa-Ômega. 1979.

MARTINS, M. A.; BRITO, D. Com maior UPP do Rio, Alemão volta à rotina de tiroteios e tráfico. Folha de São Paulo, 4 ago. 2014. Disponível em: $<$ http://goo.gl/d3q0mq>. Acesso em: 1 set. 2015.

MCCONVILLE, S. The victorian prison: England, 1865-1965. In: MORRIS, N.; ROTHMAN, D. (Org.). The Oxford history of the prison. The practice of punishment in western society. New York: Oxford University Press. 1998.

MILLER, H. S. The closed door: the effect of a criminal record on employment with state and local public agencies. Washington DC: Manpower Administration, Office of Research and Development. 1972.

MORRIS, N. The contemporary prison: 1965-present. In: MORRIS, N.; ROTHMAN, D. (Org.) The Oxford history of the prison. The practice of punishment in western society. New York: Oxford University Press. 1998.

O DIA. UPP: comunidade do Jacarezinho deve se acostumar com abordagens. O Dia, 5 abr. 2013. Disponível em: <http://goo.gl/C2hjeR>. Acesso em: 1 set. 2015.

O'BRIEN, P. The prison on the continent. Europe, 1865-1965. In: MORRIS, N.; ROTHMAN, D. (Org.) The Oxford history of the prison. The practice of punishment in western society. New York: Oxford University Press. 1998.

OECD. LSF by sex and age-indicators. 2015. <Disponível em: http://stats.oecd.org/ Index.aspx?DatasetCode=LFS_SEXAGE_I_R>, Acesso em 1.set.2015.

OLIVEIRA, F. de. Crítica à razão dualista. O ornitorrinco. São Paulo: Boitempo. 2008.

OST, S.; FLEURY, S. O mercado sobe o morro. A cidadania desce? Efeitos socioeconômicos da pacificação no Santa Marta. Dados, Rio de Janeiro, v. 56, n. 3. 2013.

PAGER, D. The mark of a criminal record. American Journal of Sociology, v. 108, n. 5, mar. 2003.

PATRIQUIN, L. Agrarian capitalism and poor relief in England, 1500-1800. New York: Palgrave. 2007. 


\section{heVistg ent paUtg}

\} PARADIGMAS DE POLÍTICA PENAL E SENTIDO ECONÔMICO - OLIVEIRA, P. R. \}

DOI: 10.12957/REP.2016.25402

QUINLIVAN, J. T. Burden of victory: the painful arithmetic of stability operations. RAND Review, v. 27, n. 2. 2003. Disponível em: <http://www. rand.org/pubs/periodicals/rand-review/issues/summer2003/burden.html>. Acesso em: 1 set. 2015.

REAVES, B. A. Local police departments, 2013: personnel, policies and practices. Washington DC: Bureau of Justice Statistics. 2015.

RIO DE JANEIRO. Lei № 6681 de 15 de janeiro de 2014. Disponível em: <http://alerjln1.alerj.rj.gov.br/contlei.nsf/69d90307244602bb032567 e800668618/ae379b7ffe74672f83257c620061a9bd?OpenDocument>. Acesso em 1.set.2015.

RODRIGUES, L. Especulação imobiliária sobe do asfalto para a favela. Jornal do Brasil, 18 mar. 2014. Disponível em: <http://jb.com.br/.eicU>. Acesso em: 1 set. 2015.

ROTMAN, E. The failure of reform. United States, 1865-1965. In: MORRIS, N.; ROTHMAN, D. (Org.) The Oxford history of the prison. The practice of punishment in western society. New York: Oxford University Press. 1998.

RUSCHE, G.; KIRCHHEIMER, O. Punição e estrutura social. Rio de Janeiro: Revan. 2004.

SCHOTT, R. Grupo de moradores do Santa Marta protesta contra ação de PM na favela. O Dia, 9 mar. 2015. Disponível em: <http://goo.gl/iqyyuc>. Acesso em: 1 set. 2015.

SHARPE, J. A. Crime in early modern England, 155-1750. New York: Routledge. 1999.

SOARES, R. Justiça expede mandado coletivo e polícia pode fazer buscas em todas as casas do Parque União e da Nova Holanda. Extra, 29 mar. 2014. Disponível em: <http://goo.gl/jvHzLm>. Acesso em: 1 set. 2015.

STERN, L. T. The effect of the depression on prison commitments and sentences. Journal of Criminal Law and Criminology, v. 31, n. 6. 1941.

TSP. The Sentencing Projetct. Report of The Sentencing Project to the United Nations Human Rights Committee regarding racial disparities in the United States criminal justice system. Washington DC: The Sentencing Project. 2013.

THOMPSON, E. P. Time, work-discipline and industrial capitalism. In: Customs in common. Pontypool: Merlin Press. 2010.

VOGEL, R. D. Capitalism and incarceration revisited. Monthly Review, v. 55, n. 4, set. 2003.

WACQUANT, L. Punir os pobres. A nova gestão da miséria nos Estados Unidos. Rio de Janeiro: Revan. 2013. 


\section{ReVistg all pautg}

\} PARADIGMAS DE POLÍTICA PENAL E SENTIDO ECONÔMICO - OLIVEIRA, P. R. |

DOI: 10.12957/REP.2016.25402

WALMSLEY, R. World Prison Population List (tenth edition). London: Internation Centre for Prison Studies. 2013.

WEST, H. C. Prison inmates at midyear 2009 - Statistical tables. Washing DC: Bureau of Justice Statistics. 2010.

WESTERN, B. Criminal background checks and employment among workers with criminal records. Criminology and Public Policy, v. 7, n. 3, ago. 2008.

Recebido em 06 de dezembro de 2015.

Aprovado para publicação em 25 de agosto de 2016.

DOI: $10.12957 /$ rep.2016.25402

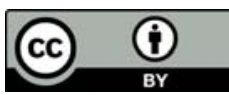

A Revista Em Pauta: Teoria Social e Realidade Contemporânea está licenciada com uma Licença Creative Commons Atribuição 4.0 Internacional. 